\title{
ESTUDO EXPERIMENTAL ACERCA DA CINÉTICA DE REMOÇÃO DE DEPÓSITOS DE PROTEÍNA DE LEITE USANDO ELETRÓLISE
}

\author{
G. A. P. SILVA ${ }^{1}$, J. S. VIEIRA ${ }^{1}$, B. H. O. PINHEIRO ${ }^{1}$, C. A. ALVARES ${ }^{1}$ e R. GEDRAITE ${ }^{1}$ \\ ${ }^{1}$ Universidade Federal de Uberlândia, Faculdade de Engenharia Química \\ E-mail para contato: guilhermeaugustoequi@gmail.com
}

\begin{abstract}
RESUMO - Este artigo apresenta os resultados do estudo experimental sobre a cinética de remoção de depósitos à base de proteínas de leite, comparando os processos com e sem a aplicação de eletrólise. O estudo foi baseado na técnica de limpeza tradicionalmente empregada em sistemas de limpeza CIP da indústria, envolvendo o emprego de solução detergente alcalina. $\mathrm{O}$ uso da eletrólise se mostrou mais eficaz na remoção dos depósitos de incrustação a base de proteínas de leite, apresentando maior taxa de variação inicial no comportamento temporal da relação entre as concentrações instantânea e final.
\end{abstract}

\section{INTRODUÇÃO}

A técnica de limpeza Clean-in-Place (CIP) é amplamente utilizada na indústria de alimentos e na indústria farmacêutica, dentre outras, visando evitar a parada de produção e a desmontagem parcial ou total dos equipamentos de processamento. Sabe-se que diversas pesquisas têm sido realizadas nos últimos anos para procurar formas de melhorar o procedimento (Bansal e Chen, 2006; Bremer et al., 2006). Tanto a tensão de cisalhamento aplicada quanto as reações químicas entre o fluido em escoamento e os depósitos formados são importantes na remoção de incrustações. A indústria de laticínios sofre de problemas específicos associados com a limpeza de equipamentos de processo, incluindo trocadores de calor (Georgiadis et al., 1998). Presentemente, o procedimento de limpeza envolve a lavagem do maquinário com solução detergente diluída, a fim de remover adequadamente os resíduos e incrustações que tendem a favorecer a contaminação. Depois de terminada a limpeza, o equipamento de processo deve ser enxaguado criteriosamente para remover todos os vestígios dos agentes de limpeza.

Este trabalho apresenta os resultados do estudo experimental desenvolvido, contemplando o comportamento temporal da cinética de remoção de resíduos de leite em seção de testes, desenvolvida especificamente para esta finalidade, sem e com a aplicação de eletrólise, durante a etapa de limpeza alcalina.

\section{MATERIAIS E MÉTODOS}

Os experimentos foram conduzidos usando o sistema apresentado na Figura 1. Este consistiu de: (i)- um reservatório com capacidade para $20 \mathrm{~L}$, contendo solução de hidróxido de sódio a 0,5 \% em peso; (ii)- bomba centrífuga; (iii)- rotâmetro ( 0 - $5 \mathrm{~L} / \mathrm{min})$; (iv)- tubos de 
aço inoxidável 316 de 1/4" de diâmetro; (v)- fonte de alimentação de corrente contínua com tensão de saída ajustável e (vi)- seção de teste em aço inoxidável 316.

Primeiramente foi preparada a solução de leite utilizada dissolvendo-se $30 \mathrm{~g}$ de leite em pó em $200 \mathrm{~mL}$ de água destilada. Na sequência, a seção de teste foi mergulhada na solução de leite, no interior de um béquer de 1 L. Posteriormente, a solução de leite e a seção de teste foram aquecidas por aproximadamente 30 minutos na temperatura de ebulição.

Durante o procedimento anteriormente citado, a seção de teste foi recoberta com o depósito de proteína de leite. Posteriormente, a seção de teste foi resfriada por meio do escoamento de água na parte externa do dispositivo e foi feita a inspeção visual a fim de assegurar que tinha sido formado um filme contínuo em seu interior. Posteriormente, a seção de teste foi montada no protótipo de sistema CIP usado, como apresentado na Figura 1.

Figura 1 - Protótipo de sistema CIP estudado

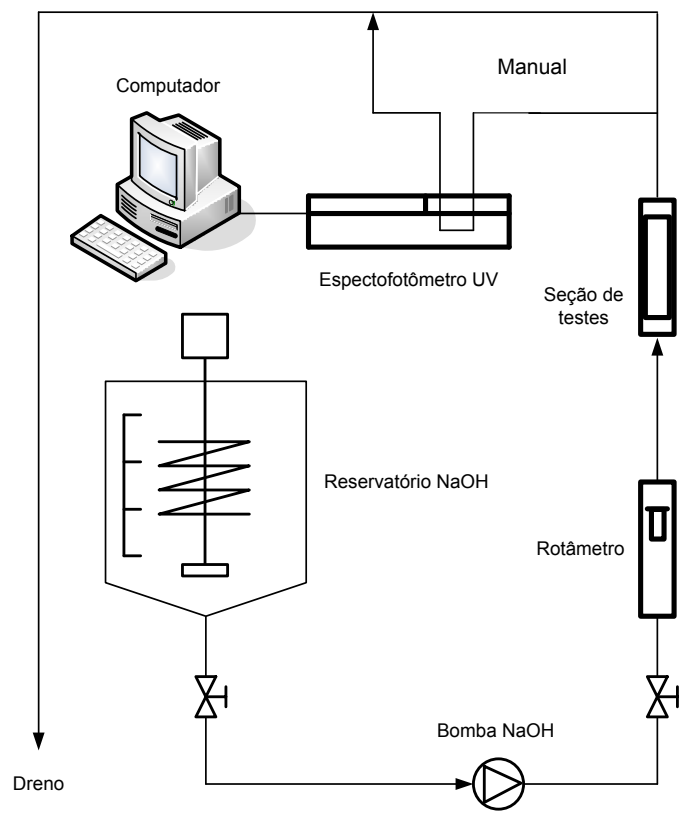

A seção de teste usada neste trabalho tem diâmetro interno igual a $15 \mathrm{~mm}$ e comprimento igual a $150 \mathrm{~mm}$. O reservatório de solução de hidróxido de sódio, mantido à temperatura ambiente, foi usado para armazenar a solução de $\mathrm{NaOH}$ empregada nos experimentos. A vazão de solução de hidróxido de sódio foi controlada por meio do ajuste manual da corrente elétrica fornecida por uma fonte de alimentação de corrente contínua para o motor de acionamento da bomba centrífuga. A vazão foi medida por meio do rotâmetro instalado à jusante da bomba. A solução retirada da seção de teste, contendo o material removido do interior da mesma foi continuamente descartada, com a retirada de amostras manualmente a cada 20 segundos de intervalo.

Para a aplicação dos experimentos envolvendo eletrólise, foi desenvolvida a adaptação apresentada na Figura 2 (Pießlinger-Schweiger, 2001). No caso de sistemas de limpeza CIP, o equipamento de processo a ser limpo é um dos eletrodos, sendo necessário introduzir um 
material metálico externo para desempenhar a função do outro eletrodo. Chen et al. (2003) afirmam que quando uma tensão elétrica é aplicada a um material metálico que apresente incrustações, em um típico sistema de eletrólise, ocorre a remoção destas incrustações com maior facilidade em função da produção de bolhas de gás oxigênio e hidrogênio que são produzidos na superfície dos eletrodos. As bolhas dos gases formados fornecem a energia adicional necessária para que ocorra mecanicamente o desalojamento das incrustações, sejam elas de origem mineral ou orgânica.

A concentração residual de resíduos removidos foi medida de acordo com a metodologia proposta por Xin et al. (2002), baseada no uso de espectrofotômetro UV. O comprimento de onda utilizado no espectrofotômetro UV foi ajustado em $256 \mathrm{~nm}$. A Equação (1) foi utilizada para calcular a concentração residual de leite com base nos valores de absorbância lidos no espectrofotômetro UV.

$$
A b s=0,00692 \times C+0,16922
$$

Figura 2 - Seção de testes adaptada para os experimentos com eletrólise

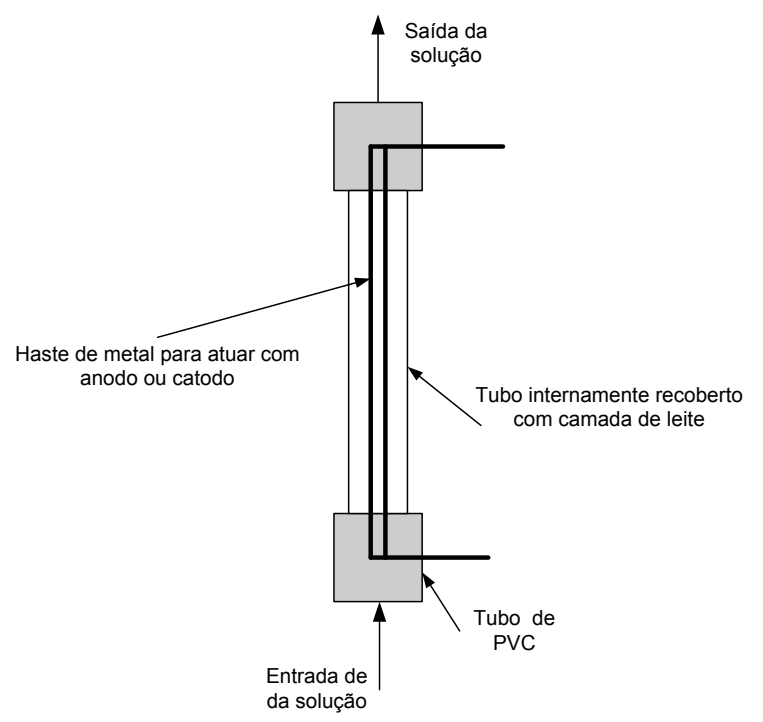

\section{RESULTADOS E DISCUSSÃO}

Os ensaios foram executados usando os seguintes valores de vazão: $2,5 \mathrm{~L} / \mathrm{min}$ e 3,0 L/min. As operações de limpeza foram executadas durante 300 segundos para cada uma das vazões testadas. Os experimentos foram realizados em triplicata. Na Figura 3 são apresentados os resultados obtidos para o processo de limpeza usando a técnica sem eletrólise para as vazões de 2,5 L/min e de 3,0 L/min respectivamente. Na Figura 4 são apresentados os mesmos resultados obtidos para o processo de limpeza baseado em eletrólise para os mesmos valores de vazão. Os regimes de escoamento do fluido de limpeza foram ambos turbulentos, com $\mathrm{Re}=3.536,78$ para 2,5 L/min e $4.244,14$ para 3,0 L/min.

Figura 3 - Comportamento temporal da

Figura 4 - Comportamento temporal da 
relação C/C0 para as vazões estudadas sem eletrólise

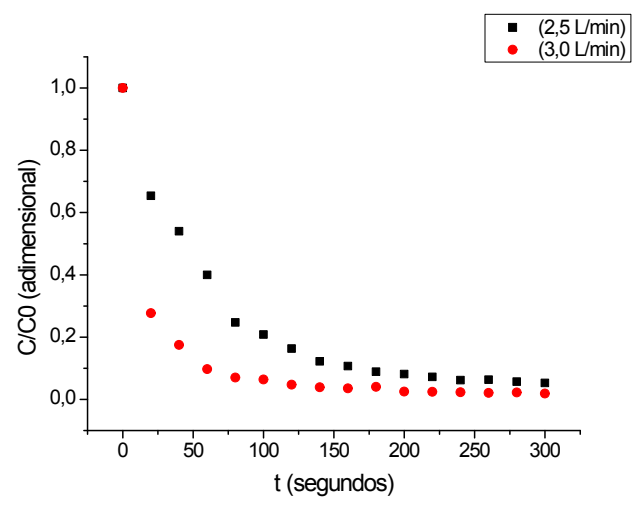

relação $\mathrm{C} / \mathrm{C} 0$ para as vazões estudadas com eletrólise

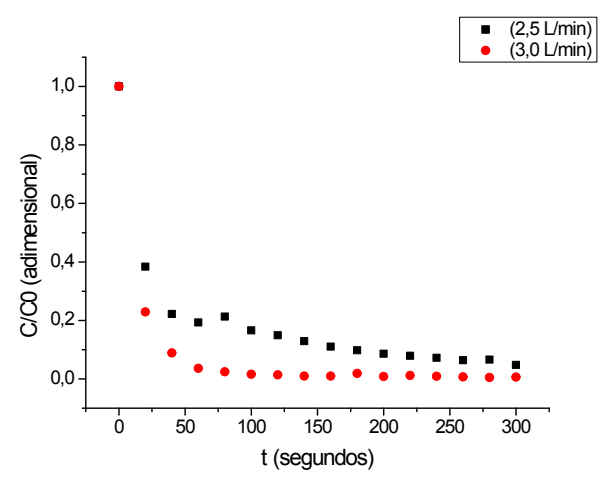

Com base nos resultados obtidos nos experimentos e apresentados na Figura 3, pode-se afirmar que para os ensaios sem a aplicação da eletrólise a vazão de 3,0 L/min se mostrou mais efetiva na remoção dos resíduos em comparação com a vazão de $2,5 \mathrm{~L} / \mathrm{min}$. Tal fato era de se esperar, pois uma maior turbulência promove uma melhor remoção dos resíduos (Gormezano, 2007). A cinética de remoção dos resíduos apresentou comportamento que pode ser modelado matematicamente como uma função de transferência de sistema de $1^{\text {a }}$ ordem, a qual pode ser adequadamente caracterizada pelo ganho e pela respectiva constante de tempo, sendo esta última o critério adotado para a análise da velocidade de resposta de sistemas dinâmicos (Ogata, 2000; Garcia, 2005). Fazendo a análise do comportamento das duas cinéticas no trecho inicial da curva de reação do processo pode-se verificar que a constante de tempo para a vazão de $3,0 \mathrm{~L} / \mathrm{min}$ foi de aproximadamente 22 segundos $\left(\mathrm{R}^{2}=0,988141\right)$ ao passo que para a vazão de $2,5 \mathrm{~L} / \mathrm{min}$ foi de 55 segundos $\left(\mathrm{R}^{2}=0,997499\right)$.

Considerando os resultados obtidos nos experimentos e apresentados na Figura 4, podese afirmar que para os ensaios com a aplicação da eletrólise a vazão de 3,0 L/min também se mostrou mais efetiva na remoção dos resíduos em comparação com a vazão de $2,5 \mathrm{~L} / \mathrm{min}$. A principal diferença pode ser verificada no comportamento da curva que representa a relação $\mathrm{C} / \mathrm{C} 0$ no inicio do processo. Fazendo a análise do comportamento das duas cinéticas no trecho inicial da curva de resposta do processo, pode-se verificar que a constante de tempo para a vazão de $3,0 \mathrm{~L} / \mathrm{min}$ foi de aproximadamente 17 segundos $\left(\mathrm{R}^{2}=0,996263\right)$ ao passo que para a vazão de $2,5 \mathrm{~L} / \mathrm{min}$ foi de 25 segundos $\left(\mathrm{R}^{2}=0,97975\right)$. Percebe-se claramente que o processo conduzido com a aplicação da eletrólise foi mais rápido do que o processo normal, sem o uso da mesma.

Nas Figuras 5 e 6 são apresentados os resultados do processo de limpeza considerando a comparação entre os dois processos - com e sem a aplicação de eletrólise - para as vazões de 2,5 L/min e 3,0 L/min respectivamente.

Com base nos resultados obtidos nos experimentos e apresentados na Figura 5, pode-se afirmar que, para os ensaios com a aplicação da eletrólise, para a vazão de $2,5 \mathrm{~L} / \mathrm{min}$ a remoção dos resíduos se mostrou mais efetiva, apresentando uma maior velocidade no início do processo. Deve ser enfatizado o fato de que a velocidade foi medida considerando-se como critério o tempo que o sistema demora em alcançar uma variação aproximada de 63,2 \% da 
variação total entre o valor da concentração inicial $(\mathrm{C} 0)$ e a concentração final. Assim, foi verificado que o processo sem eletrólise demorou 55 segundos ao passo que o processo considerando a aplicação da eletrólise demorou 25 segundos aproximadamente, para alcançar a variação postulada considerando a vazão de 2,5 L/min (Ogata, 2000).

Figura 5 - Comportamento temporal da relação $\mathrm{C} / \mathrm{C} 0$ para a vazão de $2,5 \mathrm{~L} / \mathrm{min}$ com e sem eletrólise

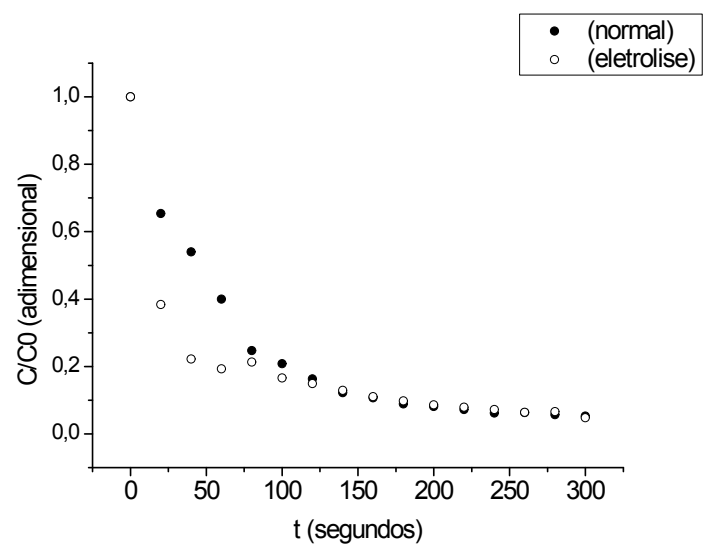

Figura 6 - Comportamento temporal da relação $\mathrm{C} / \mathrm{C} 0$ para vazão de $3,0 \mathrm{~L} / \mathrm{min}$ com e sem eletrólise

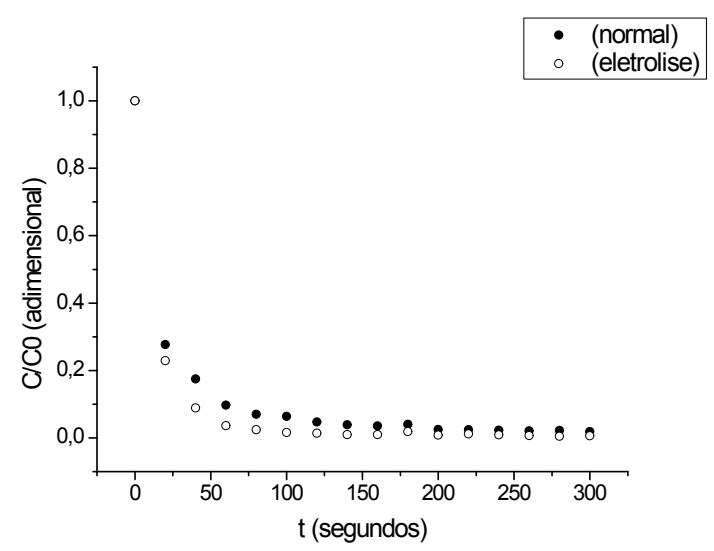

Considerando os resultados obtidos nos experimentos e apresentados na Figura 6, podese afirmar que os ensaios realizados com e sem a aplicação da eletrólise, para a vazão de 3,0 L/min, mostraram a mesma velocidade no trecho inicial da curva. Deve ser enfatizado o fato de que a velocidade foi medida considerando-se como critério o tempo que o sistema demora em alcançar uma variação aproximada de $63,2 \%$ da variação total entre o valor da concentração inicial $(\mathrm{C} 0)$ e a concentração final. A principal diferença pode ser verificada no valor da relação $\mathrm{C} / \mathrm{C} 0$ no final do processo. $\mathrm{O}$ processo conduzido com a aplicação de eletrólise alcançou valor final para a relação $\mathrm{C} 0 / \mathrm{C}$ aproximadamente igual a 0,0061 , ao passo que o processo sem eletrólise alcançou valor final próximo de 0,019 . Neste contexto, pode-se afirmar que a maior turbulência no escoamento do fluido de limpeza associado ao emprego da eletrólise contribuiu para se obter uma relação $\mathrm{C} 0 / \mathrm{C}$ de menor amplitude.

\section{CONCLUSÕES}

Considerando os resultados obtidos nos experimentos e anteriormente apresentados, pode-se concluir que o emprego da eletrólise contribui para aumentar o valor da taxa de remoção dos resíduos no processo de limpeza. Os resultados obtidos mostram, também, que o valor final da relação $\mathrm{C} 0 / \mathrm{C}$ tende a ser menor com o emprego da eletrólise para o valor de vazão de $3,0 \mathrm{~L} / \mathrm{min}$.

O principal benefício que poderá resultar da aplicação da eletrólise no processo está relacionado ao menor tempo de processamento consumido nas etapas tipicamente empregadas em sistemas de limpeza CIP na indústria, especialmente na etapa de circulação do detergente alcalino. Adicionalmente, poderá haver menor gasto de produtos químicos e de água de 
lavagem para remoção dos resíduos entre as etapas, haja vista o fato da taxa de remoção dos resíduos ser maior com o emprego de eletrólise.

\section{REFERENCIAS}

BANSAL, B.; CHEN, X. D. A Critical Review of Milk Fouling in Heat Exchangers. Comprehensive Reviews in Food Science and Food Safety. Institute of Food Technologists. v.5, p. $27-33,2006$.

BREMER, P.J.; FILLERY, S. \& McQUILLAN, A. J. Laboratory scale Clean-In-Place (CIP) studies on the effectiveness of different caustic and acid wash steps on the removal of dairy biofilms. Int. J. Food Microbiol., v.106 , p. 254 - 262, 2006.

CHEN, X. D.; ÖZKAN, N.; QIN, F.; XIN, H. \& LIN, L. An Effective CIP Procedure for Removing Dairy Protein Based Deposit - A Laboratory Investigation. ECI Conference on Heat Exchanger Fouling and Cleaning: Fundamentals and Applications. New Mexico, USA, 2003

GARCIA, C. Modelagem e Simulação de Processos Industriais e de Sistemas Dinâmicos. EDUSP, São Paulo, 2005.

GEORGIADIS, M. C.; ROTSTEIN, G. E. \& MACCHIETTO, S. Modeling and Simulation of Shell and Tube Heat Exhangers under Milk Fouling. AIChe Journal. v. 44, No. 4, p. 959 - 971, 1998.

GORMEZANO, L. Desenvolvimento e implementação de sistema para avaliar a cinética de remoção de resíduos presentes nos tubos de trocador de calor feixe tubular. Dissertação (Mestrado). São Caetano do Sul. Centro Universitário do Instituto Mauá de Tecnologia, 2007.

OGATA, K. Engenharia de Controle Moderno. Rio de Janeiro: Prentice Hall do Brasil, $3^{a}$ edição, 2000.

Pießlinger-Schweiger, S. Electrochemical and chemical polishing of heat exchangers. In: Heat Exchanger Fouling - Fundamental Approaches and Technical Solutions, Edited by H. Muller_Steinhagen; P. Watkinson and M. R. Malayeri. Proceedings of UE Foundation Conference on HX Fouling Held in Dovas, Switzerland, 2001.

XIN, H.; CHEN, X. D. \& ÖZKAN, N. Whey Protein-Based Gel as a Model Material for Studying Initial Cleaning Mechanisms of Milk Fouling. J. Food Sci. v. 67, ed.7, p. 2702 - 2711, 2002. 